\title{
Analysis and prospect of China's contemporary anti-terrorism intelligence perception
}

\author{
Huijie Zheng ${ }^{1}$, Zhenxing Chang ${ }^{1, *}$, Hezi $\mathrm{Liu}^{1}$, and $Y u \mathrm{Zhu}^{1}$ \\ ${ }^{1}$ Tsinghua University, Department of Engineering Physics, 100018 Beijing, China
}

\begin{abstract}
New types of weapons of mass destruction are still being developed continuously at a time when traditional violent and terrorist activities such as explosions, hijackings, and hacking are increasingly rampant. In order to prevent major losses caused by terrorist activities and bring chaos to the order of social life, the importance of obtaining terrorist intelligence is increasing. This paper analyzes China's deficiencies in intelligence perception and monitoring through collation, and summarizes the progress in the corresponding areas, and puts forward some of its own prospects for the future development of intelligence perception in China.
\end{abstract}

\section{Introduction}

Terrorism refers to certain extremists who use violence, bombs, biological and chemical weapons and other means to achieve extreme goals. Not only is it extremely easy to cause social panic, cause casualties, and damage public property, but it can also coerce state agencies to hinder their normal development. According to data, the number of deaths from terrorist activities worldwide reached 15,952 in 2018, causing direct economic losses of $\$ 33$ billion. Moreover, international terrorism activities are still frequent, showing a trend of globalization and individualization, and are no longer limited to collective crimes against a single country and region. This puts forward more severe requirements on counterterrorism.

If we regard global counter-terrorism as a war, there is no doubt that this war has not achieved the expected results. On the one hand, the investment of countries in the world in counter-terrorism remains high, on the other hand, the frequency of terrorist activities worldwide has not been effectively reduced. On the contrary, in some areas, the frequency of terrorist activities has not decreased but increased. Therefore, "the more we fight against the more terror" is a major problem we are currently facing. Moreover, China started relatively late in the fight against terrorism, and is in a catching-up position compared to other other advanced developed countries. Although the overall terrorist activities have been curbed, the threats of various terrorist incidents remain. In this regard, China needs to conduct in-depth research on terrorism in many aspects.

The phenomenon of "the more we fight against the more terror" caused by multiple reasons requires scientific and comprehensive interpretation and demonstration. This not only allows us to better understand the threat of terrorism and the anti-terrorism situation,

\footnotetext{
* Corresponding author: czxing2008@163.com
} 
but also allows us to make better targeted corresponding measures. This paper focuses on the impact of advances in science and technology on terrorist activities. In terms of intelligence collection and perception, in response to new changes and latest trends in terrorist activities, we will investigate and learn from the advanced experience of various fields at home and abroad, and predict and prospect the future development direction of China's counter-terrorism.

\section{The impact of technological progress on terrorism}

\subsection{Weapon}

The development of weapons has undoubtedly a huge impact on terrorist activities, and its development has greatly enhanced the lethality of terrorist activities. The figure below shows the comparison of the global average number of deaths per terrorist incident from 1981 to 1986 and the number of deaths from 2011 to 2016. By comparison, we can see that the lethality of terrorist attacks continues to increase. Moreover, with the rapid development of conventional weapon technology, the proportion of biochemical and radiological weapons in terrorist attacks has also increased rapidly. The Monterey Institute's "Terrorism and Weapons of Mass Destruction" data show that from 1960 to 1999, 151 terrorist attacks specifically were related to chemical, biochemical, radiological and nuclear weapons. [4]

Table 1. The global average number of deaths and injured number per terrorist incident from 1981 to 1986.

\begin{tabular}{|l|l|l|l|l|l|l|}
\hline Year & 1981 & 1982 & 1983 & 1984 & 1985 & 1986 \\
\hline Death number & 0.34 & 0.26 & 1.28 & 0.55 & 1.29 & 0.98 \\
\hline Injured number & 1.64 & 1.55 & 2.54 & 1.71 & 1.91 & 2.8 \\
\hline
\end{tabular}

Table 2. The global average number of deaths and injured number per terrorist incident from 2011 to 2016.

\begin{tabular}{|l|l|l|l|l|l|l|}
\hline Year & 2011 & 2012 & 2013 & 2014 & 2015 & 2016 \\
\hline Death number & 1.21 & 1.63 & 1.86 & 2.57 & 2.53 & 2.44 \\
\hline Injured number & 2.51 & 3.19 & 3.45 & 2.86 & 3.35 & 3.32 \\
\hline
\end{tabular}

\subsection{Traffic}

The advancement of modern transportation technology has greatly increased the space for terrorist activities. According to the International Air Transport Association (IATA) report, in 2017, the world's ten busiest airlines carried 2.23 billion passengers, and the world's total passenger capacity reached 4 billion. While the fast and convenient way of travel greatly promotes globalization, it also facilitates the movement of terrorists across regions and even across borders. According to a research conducted by the RAND Corporation from 1990 to 2001 , terrorists from other countries accounted for approximately $73 \%$ of the total number of terrorists. In addition, modern transportation technology has expanded the ways and tactics of terrorist attacks. The most representative of these was the "9.11" terrorist attacks in the United States in 2001. The "Al Qaeda" terrorist organization used hijacked passenger planes to hit the Petronas Twin Towers and the Pentagon, killing 2,996 people. On August 4, 2008, two terrorists drove a car in the Xinjiang Uyghur Autonomous Region of China to attack border guard officers and soldiers who were in a collective operation and detonated explosives, killing 17 officers and soldiers. [4,9] 


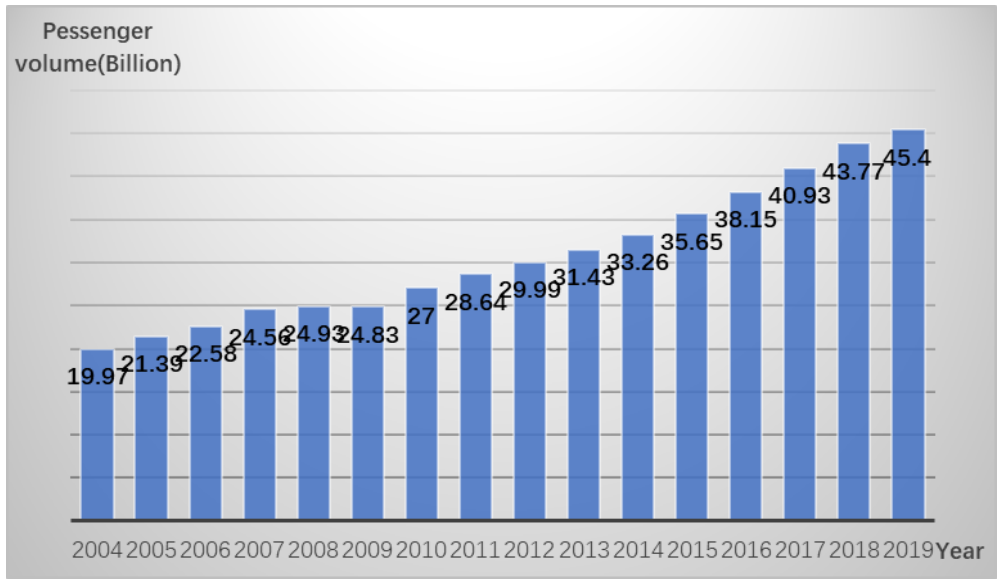

Fig. 1. Global air passenger traffic trends from 2004 to 2019.

\subsection{Information technology}

The advancement of information technology mainly refers to the impact of the revolution in communication and computer technology led by the Internet and wireless radio on all aspects of life. On the one hand, the large-scale popularization of information technology has brought a great level of convenience to human life. On the other hand, it has also provided terrorists with new channels for terrorist activities and information exchange.The main impact is:

- The emergence of modern communication technology has made it possible for terrorists to communicate across regions and organize terrorist activities, and has greatly increased the speed of terrorist information exchange.

- Terrorists can directly attack major websites and systems through the Internet, causing them to be paralyzed or maliciously tampering with a large amount of information, thereby affecting people's daily life and causing serious economic losses.

- Use online self-media and social media platforms to promote terrorism and extremist ideas. For example, after the "9.11" incident, the "Al Qaeda" organization created its own self-media platform to release information to the outside world. In addition, terrorist organizations can conduct fundraising, planning, and propaganda activities through selfmedia platforms, and generate "demonstration effects" by publishing reports on various terrorist actions to transform potential terrorists. [4,6]

\section{Countermeasures}

The precautions against terrorism mainly focus on the perception and monitoring of various types of information, which are mainly divided into two aspects: physical and geographic aspects and cyberspace aspects.

\subsection{Physical and geographic aspects}

- Establish a special air defense organization, train professional anti-terrorist personnel, and establish a professional anti-terror force to collect various types of intelligence.

- A comprehensive monitoring and early warning system is also indispensable. Combining chemical sensors for detecting various sensitive objects can effectively detect and identify all types of sensitive objects and provide comprehensive early warning. 
- Strengthen legislation to ensure that there are laws to follow.

\subsection{Cyberspace aspects}

- For daily activities such as transnational terrorist information exchange and propaganda, as well as fundraising for terrorist operations, the country needs to establish relevant institutions to effectively screen information on the Internet using methods such as big data and artificial intelligence.

- For cyber terrorist acts such as cyber attacks, the state trains information and network security related personnel, and uses technical means such as firewalls to intercept various attacks.

- Strengthen legislation and build a safe and healthy network environment.

\section{Future development direction of China's counter-terrorism}

\subsection{Counter-terrorism department}

China is becoming much stronger than before, so a unified intelligence agency is beneficial to the efficiency of China's intelligence collection and deployment and the confidentiality of intelligence. The intelligence department needs to strengthen the linkage between different government agencies, strengthen the linkage between government agencies and the people, promote the anti-terrorism of the whole people, improve the people's ability to discriminate and prevent terrorist attacks and terrorist activity intelligence, and achieve military and civilian Unite to kill the signs of terrorist actions. [5]

\subsection{Anti-terrorism law}

China is a "complex" legislation, which includes amendments to the original bills, as well as the newly promulgated "Anti-Terrorism Law" and "Cyber Security Law." Therefore, China can learn from the United States' composite legislative system to make up for the cumbersome defects of China's independent legislative system, and can better take into account the relationship between anti-terrorism and legislation to form a benign interaction. At the same time, cyber terrorism, as a new type of terrorism, has gradually emerged and is becoming more and more harmful in terrorist crimes. Therefore, the anti-cyber terrorism laws and regulations that specifically target cyber terrorist crimes also urgently need to be improved. [6]

\subsection{Cyber security}

\subsubsection{Big data and algorithms}

The new concepts brought by big data and the production and popularization of various new algorithms have brought many new trends to the research and development of intelligence.

- The popularization of big data has provided the possibility for the in-depth cross integration of various types of information, and provided a foundation for intelligence research to shift from a single field to a full field. 
- The development of big data makes it possible to use multiple data sources. In the context of big data, the difficulty of integrating complex cross-domain intelligence and multi-angle integration under different data sources is greatly reduced. In addition, big data makes it possible to apply new information resources that were previously unavailable. The popularity of the Internet has led to the continuous production of new applications. These highly diversified programs provide a variety of unprecedented information and network structures. Big data and various new analysis algorithms can use these emerging data to provide accurate results for intelligence analysis and greatly improve the rigor of intelligence research.

- The combination of big data and artificial intelligence can also promote the intelligence of intelligence research and greatly reduce the intensity of the physical work of intelligence personnel. $[7,8]$

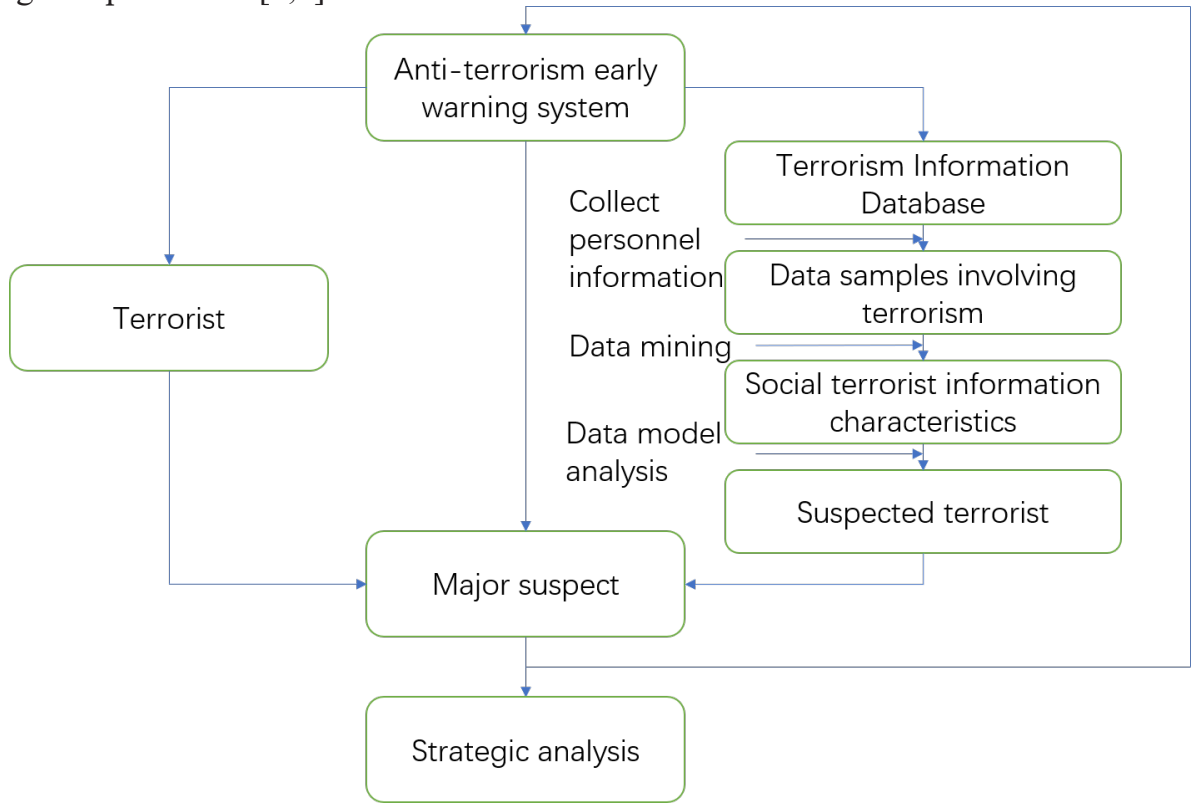

Fig. 2. Early warning process for objects of focus on terrorism.

Figure 2 is the process of using big data and data mining to automatically identify persons involved in terrorism. Using the terrorism information database and algorithms, the system will automatically identify potentially high-risk terrorist personnel, and promptly warn and notify relevant personnel to deal with it, so that terrorist activities will be suppressed at an early stage.

\subsubsection{Firewalls}

There are many development directions for firewalls in the future. We briefly introduces several aspects.

- High-speed firewall makes high-speed detection easier.

- One-way firewall ensures the one-way flow of information, which can only flow from the external network to the internal network, but not from the internal network to the external network.

- Regional joint defense technology optimizes the structure of the firewall by combining the characteristics and advantages of each firewall and learning from each other's strengths. 


\subsection{Equipment}

\subsubsection{Communication equipment}

In terms of communication equipment and satellite navigation systems, with the development and progress of technology, while continuously pursuing to improve the high performance and high precision of the positioning system, it is also necessary to improve the ability and flexibility of flexible confrontation, as well as the feasibility of services in complex environments, such as improving the flexibility and capabilities of military and civilian services, developing high-speed inter-satellite links, improving autonomous operation capabilities, and improving system flexibility through the integration of multiple systems and multiple means. For example, the integration of the US GPS and low-orbit satellite systems and the new-generation Iridium satellite system provides users with STL independent backup capabilities. What's more, to meet the needs of diversified users, multifunctional and highly aggregated to form characteristic services are also new directions for the development of satellite navigation systems. Table 3 shows that China's Beidou navigation system has already taken the lead in the world in terms of multi-functional aggregation. [1,3]

Table 3. Multi-functional integration of satellite navigation system.

\begin{tabular}{|c|c|c|c|c|c|c|}
\hline System & BDS & GPS & GLONASS & GALIEO & QZSS & NavIC \\
\hline $\begin{array}{c}\text { Radio Navigation Satellite } \\
\text { System RNSS }\end{array}$ & $\sqrt{ }$ & $\sqrt{ }$ & $\sqrt{ }$ & $\sqrt{ }$ & $\sqrt{ }$ & $\sqrt{ }$ \\
\hline $\begin{array}{c}\text { Satellite-Based } \\
\text { Augmentation System SBAS }\end{array}$ & $\sqrt{ }$ & $\times$ & $\sqrt{ }$ & $\times$ & $\sqrt{ }$ & $\times$ \\
\hline $\begin{array}{c}\text { Preciese-precision } \\
\text { positioning PPP }\end{array}$ & $\sqrt{ }$ & $\times$ & $\times$ & $\sqrt{ }$ & $\sqrt{ }$ & $\times$ \\
\hline Regional large capacity SMS & $\sqrt{ }$ & $\times$ & $\times$ & $\times$ & $\sqrt{ }$ & $\sqrt{ }$ \\
\hline Global SMS & $\sqrt{ }$ & $\times$ & $\times$ & $\times$ & $\times$ & $\times$ \\
\hline Search and rescue SAR & $\sqrt{ }$ & $\sqrt{ }$ & $\sqrt{ }$ & $\sqrt{ }$ & $\times$ & $\times$ \\
\hline
\end{tabular}

\subsubsection{Reconnaissance observation equipment}

Reconnaissance and observation equipment includes listening equipment, video detection equipment, acoustic wave detector materials and electromagnetic wave detector materials, and is developing towards strong anti-interference ability, small size, high reliability, and high endurance. At the same time, reconnaissance and observation equipment can combine artificial intelligence, big data, cloud and other emerging technologies to establish an unmanned listening system, relying on artificial intelligence machines such as drones and robots to improve the intelligence and information level of listening, and develop listening equipment that can independently complete on-site detection. Intelligent detection equipment can provide analysis results on the spot for the operator to make decisions while ensuring the detection speed and accuracy, simplifying operations. [2]

\subsubsection{Protective equipment}

Protective equipment is mainly a breakthrough in the field of materials. The main directions are: 
- Establish a complete production chain of polymer materials and composite materials, and break through the high-performance, low-cost, stable batch preparation technology and extreme environment service technology of domestic polymer and suture materials.

- Develop nanofiber materials, high-intelligence fiber materials, preventive structural composite materials and protective textile materials.

- Reorganize the upstream and downstream of the new material industry and promote the integration of production, education and research of new materials.

At present, although China has a certain distance from the international advanced level, in recent years, China's soft body armor has reached the level of NIJIIA or higher in the United States, that is, it can withstand most bullets and some hand cannon attacks.

\subsubsection{Security inspection and EOD equipment}

- Develop a multi-information fusion substance detector, and research and develop interdisciplinary substance detection technology. With the development of new technologies in various fields, the combination of detection technology and other new technologies will have broader application prospects.

- The networked system terminal is connected through Beidou satellite communication technology, 5G wireless communication technology and other networks to form a material detection and disposal network based on the Internet of Things.

- Improve the single detection ability, improve the degree of intelligence, improve the degree of compactness and make maintenance simple and convenient. [2]

\section{Summary and outlook}

The next 10 to 20 years will be an important period for China to become a global power.So a good domestic environment is essential for China, and the occurrence of terrorist activities will have a significant impact on the national environment.vTherefore, doing a good job in counter-terrorism, especially in the early stage of counter-terrorism intelligence detection and perception, plays an important role in reducing terrorist activities, eliminating terrorists, and purifying the breeding ground of terrorism. Although China is currently developing extremely fast, it is still slightly insufficient in many aspects. For example, the main core materials of anti-terrorism security inspection equipment cannot be produced locally, and the efficiency of intelligence transmission between various departments is slow. These are all problems that urgently need to be solved by China, and they also require the Chinese people to work hard for them.

\section{References}

1. W.X. Hu, Technology Strategy of Anti-Terrorism (Chemical Industry, Beijing, 2013)

2. X.D., Chen, Anti-terrorism technical equipment (Science, Beijing, 2010)

3. J. Lu, G. Zhang, G.C. Cheng, W.G. Gao, C.G. Su, Development Status and Prospect of Satellite Navigation System, Space. Eng. 29, 1-10 (2020).

4. Z. Wang, A New Theory on the Global War on Terrorism (Current Affairs, Beijing, 2018)

5. S.P. Wang, Study on Terrorism Faced by China and China's Intelligence Counterterrorism, China. Soft. Sci. 2, 1-11 (2014)

6. L.L. Gao, J.X. Gao, X. Xu, Opportunities and Challenges: Future Trend of China's Anti-terrorism Research (Part 1), J. Hunan. Coll. Police. 27, 5-13 (2018) 
7. B.X. Li, J.M. Mei, M.J. Li, Framework Design of my country's Anti-terrorism Intelligence and Early Warning System, J. Chinese. People. Secur. U. 4, 117-125 (2012)

8. Y.Wang, T.Fang, M.H. Ma, Analysis and Enlightenment of the Evolution of the US Critical Infrastructure Information Security Monitoring and Warning Mechanism, J. Intell. 35, 17-23 (2016)

9. Information on http://www.cadas.com.cn/ 